\title{
The Question of Educational Institutions'Building Sustainability in Case of Groundwater Flooding (Based on Implementation of Sendai Framework)
}

\author{
Elena $V$. Arefyeva ${ }^{1, *}$ and Dmitry $O$. Kopytov $^{2}$ \\ ${ }^{1}$ All-Russian Scientific Research Institute of Civil Defence and Emergency Management (Federal \\ Science and High Technology Centre) EMERCOM of Russia \\ ${ }^{2}$ Bauman Moscow State Technical University
}

\begin{abstract}
With the aim of increasing disaster resilience of educational institutions it is suggested to use Sendai Framework scorecards at local and object levels. The scorecards were complemented by evaluation criteria for partially drowned educational buildings and methods of working out optimal solutions for groundwater remediation. The paper suggests an approach based on solving geofiltration equations and methods of solving extremal problems.
\end{abstract}

\section{Introduction}

More than 25,000 educational institutions were damaged and more than 34,000 demolished as a result of technogenic and natural disasters in the world in the last four years (20152018). Number of disruptions in the functioning of educational institutions because of disasters exceeded 2500 in the same period [1]. Unfortunately, there is a persistent tendency for growing number of disasters and consequently growing number of disruptions in the functioning of educational institutions [1]. Because of this the UN Office for Disaster Risk Reduction (UNDRR) developed several programmes and initiatives for 2015-2030 according to Sendai Framework for disaster risk reduction (henceforth DRR) [2]. Among them is the global Campaign for Making Cities Resilient: My City is Getting Ready (henceforth Campaign) [3] and One Million Safe Schools and Hospitals initiative (henceforth Initiative) [4].

Within the scope of the Campaign and Initiative UNDRR developed scorecards for evaluating educational institutions' resiliency to disaster risk which can be applied in the Russian Federation [4-6].

The scorecards [4-6] assess educational institutions' building and infrastructure resiliency against main sources of disasters capable of causing serious damage or demolishing those objects - earthquakes, strong winds and hurricanes, floods and fires. Also, the scoreboards assess features of surrounding landscape, local geological summary,

${ }^{*}$ Corresponding author: elaref@mail.ru 
architectural and planning solutions, materials and functional components of buildings and equipment. Finally, the overall score is formed. It characterizes the level of buildings disaster risk resiliency [4-6].

However some educational institutions' buildings and facilities (henceforth EIBF) risk and resiliency measures in the scoreboards need refining and complementing with indicators characterizing some dangerous exogenic process (groundwater flooding, landslides, karsts, etc.). Also, it is essential to engage scientific and pedagogical capability of institutions of higher education to solve problems of enhancing educational institutions' building resiliency against dangerous processes. It is known that most building deformations and destructions are caused by subsoil water (including groundwater flooding) which reduces soil bearing capacity, differential foundation settlement, and so on [7].

Groundwater flooding is a complex hydrogeological process caused by natural conditions and sources, and also technogenic causes and factors which lead to disruptions of territory's hydrogeological regime and water balance. These disruptions result in water table recharge exceeding critical levels and lead to violations of conditions of EIBF operational activities and functioning.

So, EIBF safety and protection during groundwater flooding and consequent processes (landslides, karsts, erosion, etc.) can be maintained with the following measures:

1) continuous monitoring EIBF for timely detection of early signs of deformations and cracks (using scorecards [4-6]);

2) forecasting emergencies associated with hydrogeological regime and water balance disruptions on EIBF territories using mathematical simulation and special software in the learning process in institutes of higher education $[8,9]$;

3) eliminating sources of potential danger (phreatic decline, ground stabilization at EIBF foundations) $[7,11]$;

4) improving EIBF protection against groundwater flooding and consequent processes by creating effective engineering protection system [11, 12].

This paper deals with solving the problem ofeducationalinstitutions'building resiliency against groundwater flooding and consequent problems.

\section{Methods}

In order to increase EIBF resiliency against groundwater flooding through drawing up decisions on regulating groundwater regime with different drainage systems and other measures we suggest using methods for solving extremal problems. We look at the process of regulating groundwater regime as a process of arranging targeted impacts on the watertable (WT) using the corresponding control actions (for example, creating a system of drainage, drawdowns, cutoffs, screens). As a result the WT drops to the predetermined level and keeps it for the entire life cycle of the building and the surrounding territory [7,12].

The aim of control is to prevent hydrogeological metrics from going outside the predetermined range for every protected EIBF. Computations take into account depth of a building, soil properties of bases of constructions and adjacent grounds. Legitimate ranges of WT changes are determined by drainage rates, threshold and critical levels of watertables selected for each building by developers and surveyors. A peculiar feature of using drainage systems in restrained urban conditions is negative draining with washout of soil and sagging which cause additional deformations of buildings. Also, old towns have cultural layer which can be destroyed by dewatering [12]. Because of this compromise solutions are required which allow lowering the water-table to drain the building base and at the same time offering minimal drainage of soil (cultural layer) around the building. 
The cone of depression is described with the geofiltration equation, known as Boussinesk's equation, with appropriate initial and boundary conditions [13]. The required change in surface shape is performed through adjustment. Regulatory impact is realized through the system of drainage, ground water cutoffs, and screens. The regulatory impact is modeled as boundary conditions $[12,13]$.

We need to achieve the necessary EIBF drainage with minimal drainage of the surrounding territory to preserve cultural layer in old towns $(50 \%$ of towns in Russia are historical and educational institutions' buildings are often situated in their central, historical part).

This requirement can be represented as minimizing the following functional:

$$
J^{l}(h, u)=J_{n}^{l}+J_{k}^{l}, l=1,2, \ldots
$$

where $J \quad l_{n}$-summand «responsible» for the requirement of WT not exceeding critical values for the building (if $J \quad l_{\mathrm{n}}=0$, the object not flooded). This summand functional looks like this:

$$
J_{n}^{l}=A^{h} \int_{Q}\left(h(x, T, u)-h_{n}(x)\right)^{2} d x
$$

where $A \quad h$ - certain weight number, $h(x, T, u)$-level obtained as a result of drainage, $T-$ time for performing drainage, $u$ - control vector.

Control parameters - drain depth, discharge water volume, etc., $h_{n}(x)$-protected object level function, i.e. function which determines «ideal» water table for the building in the area between drain lines, $Q=\left(x_{1}-x_{2}\right)$, range of integration, $\left(x_{1}, x_{2}\right)$ - coordinates of drain lines.

$J \quad l_{k}-$ summand «responsible» for minimizing negative drainage consequences. This summand from (1) equation looks like this:

$$
J_{x}^{l}=A_{x 1}^{h} \int_{Q 1}\left(h(x, T, u)-h_{x}(x)\right)^{2} d x+A_{x 2}^{h} \int_{Q^{2}}\left(h(x, T, u)-h_{x}(x)\right)^{2} d x,
$$

where $A_{\kappa 1}, A_{\kappa 2}$ - certain weighted coefficients, defined by an expert, $h_{k}(x)$-function of WT, i.e. function which defines «ideal» level to prevent negative drainage consequences.

Upper index $(l)$ is usedto arrange computational repetitive process realizing «penalty function method» [14] for fulfillment of conditions for discovery of WT computed position (h) within acceptable limits.

The general problem of finding the desired control impact on the water table can be formulated the in following way: it is required to minimize functional $J^{l}(h, u) \rightarrow 0 \quad(1)$, taking into account that the underflow section $h(x, t, u)$ satisfies the following equations (a separate equation record for every of each areas into which the area of interest is divided according to the one-dimensional problem). For example, the equation for the first area $x_{l}<\mathrm{x}<\mathrm{x}_{1}$ looks like this:

$$
\frac{\partial h}{\partial t}=a^{2} \frac{\partial^{2} h}{\partial x^{2}}+f(x, t), \quad 0<t<T ; \quad \frac{d h}{d x}=0, x=x_{l}, h=h_{1}, x=x_{1}
$$

where $h_{1}-$ level in the first drain line (control parameter); initial distribution $h(x, 0)=h_{0}(x)$ defined and corresponds to the natural level; $f(x, t)$ - source function (precipitation, spillages, infiltration recharge).

Equations and boundary conditions in the second and third areas have a similar look $[12,13]$. Levels around grain lines $h_{1}$ and $h_{2}, u=\left(h_{1}, h_{2}\right)$ are control parameters. 
In order to minimize $J^{l}(u)$ function - virtually regardless of minimization method - it is necessary to compute gradient of $J^{l}(u)$ functional [14]. Let's show two conjugate equations for the problem (4) for the first area $x_{l}\left\langle x<x_{1}\right.$ (similar for two other areas) [12, 14]:

$$
\begin{aligned}
& \psi_{t}=-a^{2} \psi_{x x}-2 A_{l}^{h_{k}} \max \left(h_{k}-h(x, t, u), 0\right) \\
& \psi_{x}=0, x=x_{1} \\
& \psi=0, x=x_{1} \\
& \psi(x, t=T)=2 A^{h_{k}}\left(h(x, T, u)-h_{0}(x)\right)
\end{aligned}
$$

Conjugate equations (5) are solved similar to the direct problem (4) by numerical technique of passing through implicit difference scheme [14]. After auxiliary computations [13], which are omitted here, the resultant expression for the gradient of $J(u)$ functional was obtained:

$$
J^{\prime}=\left(a^{2}\left(\psi^{\prime}\left(x_{2}^{+}, t\right)-\psi^{\prime}\left(x_{2}^{-}, t\right)\right), a^{2}\left(\psi^{\prime}\left(x_{1}^{-}, t\right)-\psi^{\prime}\left(x_{1}^{-}, t\right)\right)\right), \text { if } h_{1}=h_{1}(t), h_{2}=h_{2}(t)
$$

and

$$
J^{\prime}=\left(a^{2} \int_{0}^{T}\left(\psi^{\prime}\left(x_{2}^{+}\right)-\psi^{\prime}\left(x_{2}^{-}\right)\right) d t, a^{2} \int_{0}^{T}\left(\psi^{\prime}\left(x_{1}^{+}\right)-\psi^{\prime}\left(x_{1}^{-}\right)\right) d t, \text { if } h_{1}, h_{2} \text { areindependent of } t .(6)\right.
$$

$\psi^{\prime}\left(x_{1,2}^{+-}\right)$denotes derivatives of function $\Psi^{\prime}$ in the neighbourhood of points $x_{1}$ and $x_{2}$. «+») denotes the right neighbourhood and «-» corresponds to the left neighbourhood. Hence, $\psi^{\prime}\left(x_{1}^{+}, t\right)$ and $\psi^{\prime}\left(x_{2}^{-}, t\right)$ aresolutions of the conjugate problem (5) in the $x_{1}<x<x_{2}$ area. Accordingly, $\psi^{\prime}\left(x_{1}^{-}, t\right)$ is a solution of the conjugate problem (5) in the $x_{l}<x<x_{1}$ area. $\operatorname{And} \psi^{\prime}\left(x_{2}^{+}, t\right)$ is a solution of the conjugate problem in the $x_{2}<x<x_{\kappa}$ area.

Finally, in order to find out the optimal depth of drain lines it is possible to use the gradient projection method

$$
u_{l+1}=P_{U}\left(u_{l}-\alpha_{l} J^{\prime}\left(u_{l}\right)\right), l=1,2,3
$$

with a certain initial value of $u_{0}[14] . P_{U}$ is a projection operator on feasible controls space, where the gradient of functional is determined using formulas (6).

Statement of the control problem is performed similarly. Drain lines are defined as inner sourced reversed in sign (discharges) [13].

\section{Results}

As a result of the study we suggested an approach for searching the optimal solution to control groundwater regime in order to remove groundwater flooding and minimize drainage area around EIBF with the aim of preserving cultural layer and reducing negative drainage effect. Below is an example of computations performed according to formulas (1)(7). Fig. 1 shows possible options for laying drain lines to the object. 


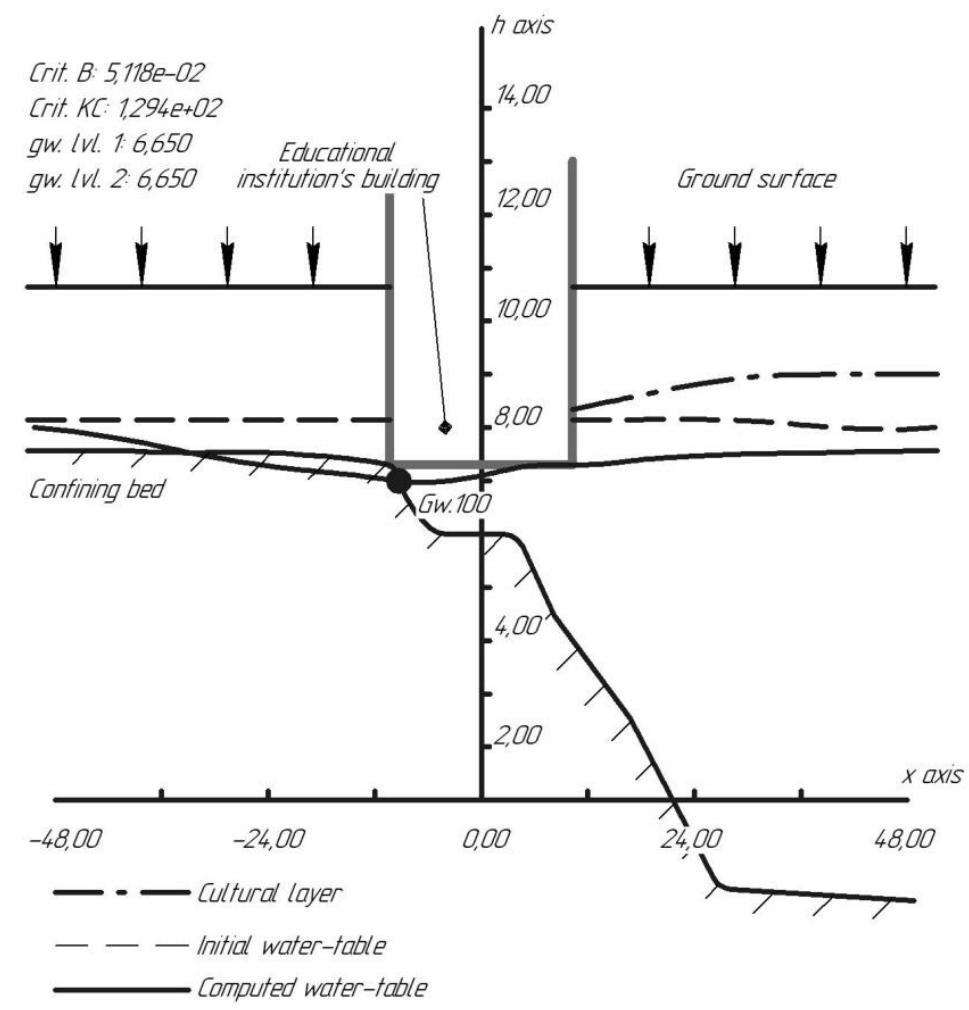

Crit. B - criterion for evaluation of drainage of the subsurface compartment of the protected object; Crit. $\mathrm{KC}$ - criterion for evaluation of soil (cultural layer) in the surrounding territory

Fig. 1. Example of calculating drain lines position for linear drainage of the EIBF in the town of Novgorod

Initial data for computations are distribution of filtered feed and initial distribution of groundwater level on given territory; soil properties - equation coefficients in mathematical models (coefficients for filtration, water return, transmissibility); boundary conditions (internal and external); protected object parameters, probable positions of drain lines building's basement other control impacts; critical level of groundwater for the object and territory. Figure 1 shows that a given drain line catches the flow and prevents flooding of the building's basement.

Various methods of drain computations which calculate optimization criteria characterizing drainage of subsurface compartment of the building's basement and drainage of the surrounding territory - will help a decision maker to choose the optimal way of groundwater remediation and, by doing so, protect the object (building) and increase its operational reliability.

\section{Conclusion}

In order to realize Sendai Framework at local level in Russian Federation we suggest using enhanced UNDRR scorecards complemented with assessment of EIBF resiliency to the groundwater flooding and consequent processes (landslides, karsts, washout, etc.). The paper suggests methods for finding the optimal solution to reduce dangerous groundwater level for EIBF. It will improve EIBF resiliency and operational reliability. 
Analyzing scientific publications concerning groundwater regime control we found no problems dealing with optimal solutions for reaching and maintaining safe groundwater level while simultaneously fulfilling opposite requirements for drainage. For this reason we had to use and adapt ill-defined extremal problem [14], rarely used in this field.

Results of the suggested approach can form a basis for making decisions towards preventing emergency situations of the groundwater flooding of educational institutions'buildings and structures. They will also supplement existingUNDRR scorecards used to evaluate objects' resiliencyagainst disasters and help improve mathematical methods and specialized software used in National (regional) crisis management centres of the Ministry of Emergency Situations of Russia and in the Training Center at Bauman Moscow State Technical University.

\section{References}

1. Monitoring of Sendai Framework for Disaster Risk for 2015-2030, https://sendaimonitor.unisdr.org

2. Sendai Framework for Disaster Risk Reduction 2015-2030 - 9-11 Ruede Varembe, CH 1202, Geneva, Switzerland, https://www.unisdr.org/files/

3. Disaster Resilience Scorecard for Cities. Detailed Level Assessment, https://www.unisdr.org

4. One Million Safe schools and Hospitals. Advocacy Guide, https://www.preventionweb.net

5. Tools for the Assessment of School and Hospital Safety for Multi-Hazards in South Asia, United Nations Human Settlements Programs (UN-Habitat) (2012)

6. I.Yu Oltian, E.V. Arefieva, V.V. Krapukhin, T.L. Liahovetz, Civil Security Technologies, 2 (52), 32(2017)

7. E.V. Arefieva, Industrial and Civil Engineering, 11, 47(2007)

8. V.A. Devisilov, , A.A. Aleksandrov, S.P. Suschev, D.O. Kopytov, Training Center at Bauman Moscow State Technical University. Safety in Technosphere, 3(2), 68(2014)

9. V.A. Devisilov, A.A. Aleksandrov, S.P. Suschev, D.O.Kopytov, A.N.Kalaidov, Safetyin Technosphere, 3(3), 55(2014)

10. M.I.Faleev, V.V.Artyuhin, E.V.Arefieva,A.V.Vereskun,O.A.Morozova, N. N.Posohov, E.M. Leonova, Managing Disaster and Natural Disaster Risks (a guide for heads of organizations), (2016)

11. A.G. Roitman, Buildings Deformation and Damage, Stroyisdat(1987)

12. E.V. Arefieva, LAP LAMBERT Academic Publishing, 6(2014)

13. E.V. Arefieva, Civil Security Technology, 13(1 (47))(2016)

14. F.Vasiliev, Methods for solving extreme problems(1981). 